\title{
Development of Elephant Conservation Based Tourism after Implementation of Logging Ban Policy in Myanmar
}

\author{
Zar Zar Win Thein¹, Zhou Jianhua1
}

${ }^{1}$ School of Economics and Management, Beijing Forestry University, No 35, Qinghua East Road, Haidian District, Beijing, Peoples Republic of China, Post Code -100083

\begin{abstract}
According to afforestation 10 years program (from 2017-18 to 2026-2027), the Republic of the Union of Myanmar, Ministry of Natural Resources and Environmental Conservation (MONREC) has agreed on a new logging ban policy for Myanmar's forest; 10-year logging ban for the Bago Yoma Region and 1-year national logging ban for the remaining areas since (2016-2017) fiscal year. Myanma Timber Enterprise (MTE), one of the state-owned enterprises, is mainly responsible for the logging operation and dragging logs from the forest with Elephants is the most well recognized as environmentally friendly logging operation in Myanmar. After implemented Myanmar's logging ban policy is great for forests, but a big challenge for MTE for the maintenance of MTE staffs and its working captive elephants in the timber industry for elephant conservation and welfare of the elephant staffs (mahouts). MTE owns more than 3000 Captive Elephants to perform logging operation, among which more than one-third is suitable for the workforce of skidding. The rest are not suiting for work as they are babies and mothers, pregnant, training, unhealthy and/or aged elephants. Nevertheless, all of the elephants are under the care and management of MTE. As a solution of logging ban policy effects on MTE, it came up with the idea of establishing Elephant Conservation Based Tourism (ECBT) in Myanmar by taking into consideration of the conservation of elephants and the welfare of the mahouts as well as an alternative way of earning income from ecotourism. Now, MTE is already implemented elephant conservation camps in a nationwide by state-owned sector. Wildlife tourism is often promoted as an activity which supports conservation by enhancing environmental knowledge, attitudes, and behavior through interpretative messaging and personal experiences with wildlife. ECBT will increase absolutely in the conservation of elephant.
\end{abstract}

Keywords: Logging Ban Policy, Elephant Conservation Based Tourism Captive Elephants

\section{INTRODUCTION}

In Southeast Asia, Myanmar is one of the countries which is rich in the huge variety of forest resources. Nowadays in Myanmar, 70 percent of the total population is rural people who have mainly depend on forest timber for their household construction material and Non-timber forest products (NTFPs) for their basic needs and hunting on wildlife also plays an important role for their daily lives. According to Forest Resource Assessment (FRA) 2015, Myanmar was a stand of the third highest deforestation rate country among other countries in the world. Largescale reforestation and rehabilitation are urgently needed in order to increase forest cover, and to compliance with the international agreement related to climate change mitigation and adaptation. Myanmar has been managing its forest resources on a sustainable basis. Myanmar Selection System was started in 1881 to achieve the sustainable yield. Status of forest cover of Myanmar is decreased from $59.97 \%$ in 1990 to $42.92 \%$, in 2015 are as follows in table 1 (FRA, 2015). 
Table 1:Forest Cover Status of Myanmar

\begin{tabular}{ccc}
\hline Year & Area (sq-mile) & $\%$ \\
\hline 1990 & 151,421 & 57.97 \\
2000 & 134,626 & 51.54 \\
2005 & 128,653 & 49.25 \\
2010 & 122,676 & 46.96 \\
2015 & 112,127 & 42.92 \\
\hline
\end{tabular}

Source from FRA, 2015

To save and improve the density and quality of forests, silvicultural practices and methods are carried out to improve the quality of the forests. Forest plantations are also established in the degraded forest areas for various purposes. Forests are managed through 10 years District Forest Management Plan for each of 68 Districts across the country. Currently, 10 year District forest management Plan (2016-2017 to 2025-2026) is being implemented.

At (2016-2017) fiscal year, Myanmar government agreed with a new policy on logging, 1-year national logging ban (2016-2017) in the whole extraction and 10-year logging ban for Bago Yoma (2016-2025). It is just new policy and focuses on rehabilitation of Myanmar forest and national inventory.

In the years of 1800 s and 1900s, during the British Colonization and Bon- May Burma Extraction Agency that occurred highly pressures on wild elephant capturing for using elephants as dragging animal in timber industry (Peter Leimgruber et al, 2011). In every year, approximately 350 population of wild elephants were captured from the wild to captive for use in the logging industry (Toke Gale 1974; Olivier 1978; Caughley, 1980; Lair 1997; Myint Aung 1997; Leimgruber et al. 2008) and they are main critical, useful and cheaper than harvesting machine.

All of the natural resources including wildlife from Myanmar is conserved and administrated by the union ministry level named Ministry of Natural Resources and Environmental Conservation (MONREC). There are two main forestry-related organizations, under MONREC: Forest Department (FD) and Myanma Timber Enterprise (MTE).

FD is mainly responsible for Conservation and Management of forests by developing Forest Management Plan/ Formulating Forest Policy \&
Laws and so on.

$>$ MTE is mainly responsible for Operations such as harvesting, processing, milling and marketing of timber.

Therefore, to perform the business sector of forest resources, MTE was born as the name of STB (State Timber Board) since 1948. Moreover, by the Forest Law (1992), MTE has a legal right of commercial harvest and sale of timber and timber products without using the Competitive Bidding System. There is no concession system practiced in Myanmar. Myanma Timber Enterprise (MTE), as a State Owned Organization, contributes to the Nation Income by systematic harvesting of the natural resources from the precious forests. As most of the harvesting is still done in the natural forests, log skidding operation cannot be accomplished without the power of elephants. Every Elephant except babies has his/her own care-taker so-called "mahout". Therefore, MTE, Elephants and their mahout and mahout' family are tightly bonded as a "big family".

As a result of implementing logging ban policy, MTE has stopped their timber extraction activity in the 2016-17 fiscal year and it has about 3000 elephants that used in logging, these elephants also need to use and conserve. When the elephants un-employed, they become angry a lot more easily and there is no work, so they are getting fat. At that time, most of the males elephants have sexual desire and it's dangerous for elephants staffs. After that, the problem of how to address the elephants and the elephant staff of the disclosed extraction agencies has emerged. Therefore. MTE established and developed ECBT for elephant conservation and welfare for mahouts (elephant staffs). So MTE is the main actor for addressing the elephant conservation case after implementation of logging ban policy. 
Table 2: Current Strength and Power of MTE (August 2017)

\begin{tabular}{llll}
\hline $\begin{array}{l}\text { Sr. } \\
\text { No }\end{array}$ & Current Workable Strength & Quantity & Remark \\
\hline 1 & Current Staff & $\mathbf{1 5 9 5 1}$ & \\
2 & Working Elephants (total of over 3000) & 1131 & \\
3 & Dozer, etc. (for Road Construction & 135 & \\
4 & Loader, etc. (for Logs Loading \& Unloading) & 203 & Extraction Department \\
5 & Truck (for Trucking) & 357 & \\
6 & Extraction Agencies & 28 & \\
7 & Elephant Conservation Based Tourism-ECBT Camps & 18 & \\
\hline 8 & Vehicles & 2482 & MTE as a whole \\
\hline 9 & Sawmills & 7 & Export Department \\
\hline 10 & Sawmills & 58 & Local Department \\
\hline 11 & Factories & 20 & Wood Based Industry \\
\hline
\end{tabular}

Source: Myanma Timber Enterprise (August, 2017)

According to Table 2, MTE currently has 15951 Staff who need to pay salary, in addition to, over of 3000 elephants also need to feed them today, 12000 MMK (Myanmar Kyat) per elephant per day. Even don't use too much vehicle when stopped harvesting needs to maintain and also has a cost and burden for MTE. As an extraction department, ECBT is the only way to maintain and conserve elephants and mahouts and received income from ecotourism.

The rest of the paper is organized as follows. The next section shows the current status of elephant conservation in Myanmar. After that describes the distribution of captive and wild elephants. Section 4 is the main part of developing of ECBT in Myanmar and then the paper ends by conclusion section 5 .

\section{CURRENT STATUS OF ELEPHANT CONSERVATION IN MYANMAR}

The Asian elephant (Elephas maximus) is a globally threatened species and its survival depends on maintaining viable habitats and understanding the population status of the species (Sukumar, 1989; Santiapillai and Jackson, 1990). The Asian elephants have subspecies name according to the place they are found, in Myanmar, called Elephas maximus brimanicus (U Khin Zaw, GAJAH 17:9-22). The captive elephant has always been considered the backbone of the country's economy because $50 \%$ of the timber harvesting was carried by elephant power and around 3000 working elephants are needed for the timber industry in Myanmar (Zaw, 1998). To restock captive strength for timber harvesting, elephants have been captured from the wild (Salter, 1983; Htut, 1993).

2.1 Distribution of Captive and Wild Elephants In Myanmar

In Myanmar, there have two kinds of Captive Elephants: State-owned and Private owned. According to MTE estimated data in 2017, the number of State-owned Elephants were 3042 (30-112017) and Private Owned were 2000-2500 (estimate), moreover, the number of Wild Elephants were 15002000 (estimate). They are widely distributed in 10 regions of Myanmar and 37\% of the total population are allocated in Sagaing Region with the 1109 number of elephants and Bago (Pegu) region stands the second largest distributed area which is 10 -years logging ban policy affected area, can see in figure 1 . 

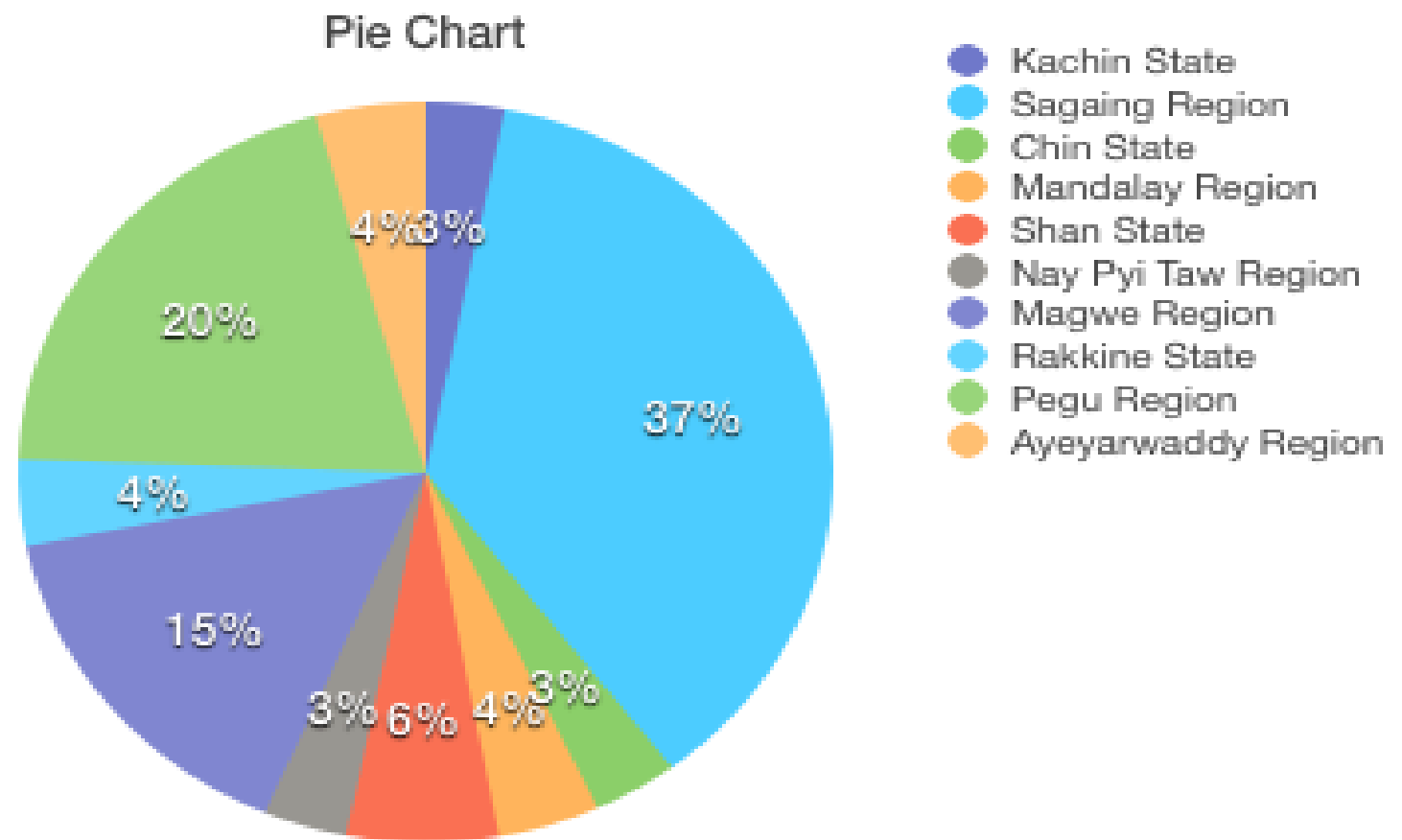

Figure 1: The distribution of Captive and Wild Elephants in Myanmar (in \%)

Source; Myanma Timber Enterprise, Myanmar

Table 3: Estimates of Myanmar's wild and State-owned Captive Asian elephant population from 1970-current

\begin{tabular}{|c|c|c|c|}
\hline Year & Wild Estimate & Captive Number & Remark \\
\hline 1970 & 7008 & - & \\
\hline 1980 & 5508 & - & Estimated number \\
\hline 1990 & 4639 & 2925 & \\
\hline 2000 & $<4000$ & 2715 & \\
\hline 2002 & 6000 & - & \\
\hline 2003 & $4000-5000$ & - & \\
\hline 2004 & $<2000$ & - & \\
\hline 2004-current & $1500-2000$ & over 3000 & \\
\hline
\end{tabular}

Source from Forest Department

According to the table 3 , the number of captive elephants are more than wild elephants and $75 \%$ owned by State, MTE and population of wild elephants are significantly declined in the 1970s and 1980 s due to a lot of capturing for the timber industry.

2.2 Law and Regulation of Elephant Conservation in Myanmar

Conservation of elephant was started through the Elephant Preservation Act of 1879 and spread out by subsequent laws including the Burma Wildlife Protection Act of 1936 (revised 1956), and the Protection of Wildlife and Wild Plants and Conservation of Natural Areas Law in 1994 (Peter Leimgruber, 2011). Wild elephants have now considered a completely protected species (Lair
1997; Myint Aung 1997; Uga 2000). For the completely protected species, according to "The Protection of Wildlife and Wild Plants and Conservation of Natural Areas Law (1994), No (16 )" The Director-General may, with the approval of the Minister:- (b) permit for extraction, transportation and possession of protected wild plants from the protected natural area to enable experiment and reproduction to a person who has been permitted to conduct research on them to enable scientific research.

Elephants play a critical role in Myanma history, culture, and economy, as a symbol of the power of a Kingdom / Country, as a symbol of good fortune, as a symbol of the workforce. In timber Industry, Elephants are essential for harvesting operation of 
Skidding Logs from a complicated naturally grow forests. Nowadays, the role of elephants is extended to the Ecotourism Sector! Therefore, Elephants are precious and need to take good care of them. Elephants are totally protected wildlife species in Myanmar (Yin, 1967 and Blower, 1985). According to Wildlife Protection (Amendment) Act 1956, prohibits hunting, capture, possession, sale, or purchase of live or dead elephants or their products without proper permission. In captive elephants, there are two kinds of captive, 'State-owned' and 'Private owned'. The term 'State-owned elephants' means the verification of those registered at the Forest Department at the edge of 3 months and used at the Myanma Timber Enterprise (MTE), which are under the control of the Ministry of Natural Resources and Environmental Conservation, Myanmar. In the Elephant Regulation Act of 1951, all domesticated elephants - state-owned and private owned elephants should be registered by the Forest Department at the age of three months with the main intention being to prevent the illegal wildlife trade and the illegal capture and poaching of elephants (Working People's Settlement Board, 1982).

Myanmar government has been a signatory to CITES concerned with elephants since 1997. The elephants used in timber industry are derived from two sources; wild captured elephants and captive-born elephants.

\subsection{Role of MTE in Elephant Conservation}

As Elephants are precious and indispensable for MTE, vets are assigned to take care of the health of captive elephants as well as wild. In MTE at present, there have 52 veterinarians who care about the elephant to be healthy. Moreover, MTE has three Mobile Clinic Vehicles which aided SPANA (Society for the Protection of Animals Abroad) to carry out the activities to private and wild elephants: Vaccination ,Deworming ,Remove from old Abscess ,Treatments (Supportive \& Therapeutic) ,Foot Care Management ,Mahouts Education .

MTE has systematic healthcare program with mobile clinic and free veterinary service program by the collaboration with MTE and SPANA (Society for the Protection of Animals Abroad). The establishment of Emergency Elephant Response Unit (EERU) is responsible for card and management of captive elephants. Lost of habitat and Death of Wild elephants are increasing because of hunting or other causes.

To address poaching and Human-Elephant conflict tissues, EERU (Emergency Elephant Response Unit) has been developed by MTE in order to mitigate the conflict between human and elephants. So far, there are Eight EERU throughout the country, where activities such as education and awareness program, regular patrolling around the boundary, Translocation of wild elephants pushing back to the wild, translocation, Patrolling the boundary are carried out.

\begin{tabular}{lccc} 
3.DEVELOPING & OF & \multicolumn{2}{c}{ ELEPHANT } \\
CONSERVATION & BASED & TOURISM IN \\
MYANMAR & & & IN
\end{tabular}

Logging Ban in 2016-2017 and the depletion of the natural forests in Myanmar lead to the disclosure of some Extraction Agencies of MTE. After that, the problem of how to address the elephants and the elephant staff of the disclosed extraction agencies has emerged. As a solution to this situation, MTE came up with the idea of establishing Elephant Conservation Based Tourism in Myanmar by taking into consideration of the conservation of our elephants and the welfare of the elephant and mahouts, the forests and the environment, logging has immediately affected on elephants.

\subsection{Myanmar Ecotourism Policy and Management Strategy}

In Myanmar Ecotourism Policy and Management Strategy, there are six strategic programmes, which are operating in the establishment of the ecotourism sites, mitigating the negative impacts by developing the management plans. And creating the facilitate productive relationships between local communities and service providers. Establishment of infrastructure makes special attention to visitors and doing research and monitoring for developing ecotourism. Myanmar ecotourism will become a distinctive brand and component of the country's tourism product, these are;

- Strengthen Institutional Arrangements,

- Develop Ecotourism Management Plans,

- Engage Local Communities,

- Invest in Infrastructure and Responsible Business Models,

- Strengthen Research and Monitoring Frameworks, and Strengthen Marketing and Interpretation 
Table 4: Income Currency from ECBT in Myanmar (financial Year 2013-2018) (MMK= Myanmar Kyat)

\begin{tabular}{|c|c|c|c|c|}
\hline $\mathrm{Sr}$. & Location & Name & $\begin{array}{c}\text { Income (MMK) } \\
\mathbf{M}\end{array}$ & Remarks \\
\hline 1 & Nay Pyi Taw & Nga Laik & $64,517,000$ & \\
\hline 2 & Bamaw & Walma & 260,000 & \\
\hline 3 & Maw Laik & Pyarswal & $3,639,000$ & \\
\hline 4 & Pyin Oo Lwin & Die Doat & $1,154,000$ & \\
\hline 5 & Pathein & Thit Kadoe Ae & 473,000 & \\
\hline 6 & Rakhine & Ta Lae & $7,914,000$ & \\
\hline 7 & Pathein & Moe Ma Kha & 473,000 & \\
\hline 8 & Kathar (West) & Nat Pauk & $55,716,000$ & 1-year National Logging Ban Area \\
\hline 9 & Taungoo & Phyo Kyar & $24,849,000$ & \\
\hline 10 & Bago & Win Gabaw & $55,716,000$ & \\
\hline 11 & Bago & Myaw Yaw Gyi & $16,657,500$ & \\
\hline 12 & Pyay & Nat Myaw & $7,971,000$ & \\
\hline 13 & Tharyarwadi & $\begin{array}{l}\text { Myaing Hay } \\
\text { Won/Moukkar }\end{array}$ & $3,159,500$ & $\begin{array}{c}\text { 10-years Logging Ban Areas (Bago } \\
\text { Yoma) }\end{array}$ \\
\hline 14 & Monywa & Alaungkathapha & $7,600,000$ & Seasonal Camps (Dec-April) \\
\hline & Total & - & $204,092,500$ & $204,092,500$ \\
\hline
\end{tabular}

Source: Myanma Timber Enterprise 
MTE has already established the Elephant Conservation Camp since 1993, but it was developed to the public in 2013 and then more and more developed widely in the whole country in 2016-17 while implementing of logging ban policy. Remarkable income amount of ECBT is shown in Table 4 for 1-year and 10-year logging ban areas.

\subsection{Elephant Conservation Based Tourism in} Myanmar

There are so many reasons and causes that's why ECBT need for the elephants and State-owned Enterprise, MTE, among of them, the following 4 reasons are critical things for developing ECBT after implementation of logging ban policy.

(1) financial daily cost for elephant feeding and maintaining; In MTE at present, performed the cost of over 3000 captive elephants and paid the salary for around 3400 mahouts (elephant staff), the total cost of elephant just feeding is 12000 Myanmar Kyat (MMK) per elephant per day. So, developing of ECBT is the best way of conservation elephants and sustain the living standard of mahouts.

(2) Increasing rate of elephant poaching; The critical things of the elephant killed were destroyed for ivory and skin. Therefore, conserving the elephants in elephant conservation camps of MTE is an alternative way of protecting from elephant poaching.

(3) Reducing Human-elephant conflict (HEC) if translocation to the forest; By conserving the elephant as the captive in MTE and by developing ECBT which can reduce $\mathrm{HEC}$ by a significant amount. HEC occurred especially in the agriculture fields which reported human injuries and loss of life. ECBT is the alternative way of reducing the incidence of HEC encounters and releasing awareness to the community by touching elephant behavior closely.

(4) Male Elephant Metabolism: After implementation of logging ban policy, elephants no work and they are getting fat that makes male elephants have a desire for sex according to male elephant metabolism. During that time, they are very dangerous and difficult to control. Therefore, ECBT arrange the reasonable duration of work hours to elephant even don't have for dragging logs and it balances the life of the elephant.

The ECBT camps have been emerged starting from August 2016. Objectives of ECBT are:

$>\quad$ to develop Elephant Conservation Based Tourism,

$>\quad$ to create alternative job opportunities for elephant staff (Mahout) and local people in order to promote the welfare of Mahout Family,

> to promote understanding of the elephants' habit, behavior and the nature of their habitation in order for the civilians to love and treasure the elephant more,

$>\quad$ to support the conservation of natural landscape by means of establishing ECBT,

$>\quad$ to supply national income by creating elephant camps as the non-smoking industry. 
Table 5: Elephant Conservation Camps in Myanmar

\begin{tabular}{|c|c|c|c|c|}
\hline Sr. & Location & Name & Opening Date & No of Elephant \\
\hline 1 & Tharyarwadi & Myaing Hay Won & $1-1-1993$ & 34 \\
\hline 2 & Kathar (West) & Nat Pauk & $1-1-2008$ & 19 \\
\hline 3 & Pyin Oo Lwin & De Doat & $30-8-2010$ & 8 \\
\hline 4 & Pathein & Ngwe Saung & $20-12-2013$ & 5 \\
\hline 5 & Maw Laik & Pyarswal & $27-7-2013$ & 9 \\
\hline 6 & Bamaw & Walma & $15-9-2014$ & 5 \\
\hline 7 & Taungoo & 20-Mile Hospital & $1-1-2016$ & 57 \\
\hline 8 & Bago & Myaw Yaw Gyi & $12-8-2016$ & 24 \\
\hline 9 & Rakhine & Ta Lae & $1-11-2016$ & 10 \\
\hline 10 & Taungoo & Phyo Kyar & $1-11-2016$ & 14 \\
\hline 11 & Bago & Win Gabaw & $3-11-2016$ & 19 \\
\hline 12 & Pyay & Nat Myaw & $3-12-2016$ & 5 \\
\hline 13 & Pyay & Dr. Brandis & $20-1-2018$ & 3 \\
\hline 14 & Tharyarwadi & Moukkar & 4-1-2018 & 13 \\
\hline 15 & Pathein & Thit Kadoe Ae & $1-1-2017$ & 4 \\
\hline 16 & Pathein & Moe Ma Kha & $1-2-2017$ & 7 \\
\hline 17 & Nay Pyi Taw & Nga Laik & $18-5-2017$ & 20 \\
\hline 18 & Tharyarwadi & Moukkar & $4-1-2018$ & 13 \\
\hline 19 & Taung Gyi & Shan Yoma & $13-2-2018$ & 8 \\
\hline & Total & 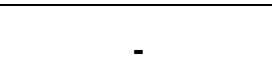 & 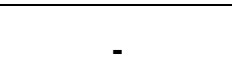 & 279 \\
\hline
\end{tabular}

Source: Myanma Timber Enterprise

According to Table 5, although elephant conservation camps already established and initiated before logging ban, ECBT developed so fast at 2016 of start year of logging ban, mainly in Bago Yoma Region. ECBT stimulates the awareness and conservation of elephants by spreading the news about elephants

\subsection{ECBT Development Process}

Tourism creates not only various chance of employment opportunities but also develop infrastructures in initiated tourism related places. On the other hand, people interest in traditional culture and beauty of environment in tourism places. In addition to, promote the traditional food and traditional costume and also develop awareness among the people the knowledge concerned with the conservation of the environment. Myanmar government have been trying to be sustainable and developed ECBT by initiating the following activities:

(1) Discussing and collaboration with Ministry of Hotel and Tourism; to develop the sustainable tourism of ECBT, government do a group collaboration section with Ministry of Hotel and Tourism, Owners Travelling Business Company, Tour Guides and people who interesting in ECBT at Head Office of MTE, Yangon, Myanmar in 2018.

(2) Initiating the "Elephant Lake Camp" which intended the biggest elephant conservation center in Southeast Asia; Myanmar government are initiating now 10-year project on the biggest elephant conservation center with the collaboration with Four Paws International NGO, Australia and Mingalar Myanmar organization at 'Ye Nwe Forest Reserve Area', Bago Region, Myanmar. The objectives of establishing "Elephant Lake Camp" are; to conserve the elephant preventing from the high pressure on poaching for illegal ivory and skin trade to other 
countries and save the wild elephant from decreasing numbers years by years, to conserve the timber elephants which don't have work after implementation of logging ban policy and so on. According to 10 -year project, the government will be intended to establish the biggest elephant hospital in there and arrange the elephant to enjoy close to nature without touching elephant body like other elephant camps.

(3) Attending the workshop on elephant conservation activity and arranging training program to Thailand; Veterinarian, elephant healthcare specialists, and foresters from MTE have been joining the workshop and training activities in other countries and especially in Thailand to adopt and share the methods and techniques of conserving elephants and developing of ECBT.

(4) Promoting people awareness and participation in elephant conservation camps; ECBT sharing the information about one of the totally protected species, elephant conservation and see the daily lives of mahouts.

\subsection{Future Trend of ECBT}

Due to developed transportation and information technology, people change their social attitudes and trends towards nature and wildlife, and the satisfaction level of interaction with animals behavior, tourism centered on wildlife in captive and semi-captive settings is becoming increasingly popular (Nick Kontogeorgopoulos,2008). For example, "elephant conservation camp" in Thailand, wildlife tourism in a semi-captive setting is the expanding of elephant conservation tourism, tourists take a part in a variety of ways with captive elephants. ECBT cerates the only viable legal option for elephant owners and handlers to earn income. Myanmar government willing to establish ECBT like in Thailand after implementation of logging ban policy.

In Thailand, the tourism industry is developed quickly in every section, mainly ECBT and beautiful beaches are the most tourist attraction places there. Also, the one-month visa-free system in Thailand encourages tourists to visit and enjoy in nature and beauty of Thailand. Myanmar also have a lot of beaches, beautiful places of tourist attraction and around (20) elephant conservation camps. Therefore, developing ECBT will create a best solution of elephant conservation and can increase the GDP from to the tourism industry .

\section{CONCLUSION}

Elephants Conservation Based Tourism (ECBT) developed by the government sector and state-owned enterprise, MTE must be carried out by supporting the operation that develop a licensing system for elephants employed in tourism, develop do and don't for elephant tourists and regulate mahouts working in elephant tourism in order to facilitate in service and develop a ECBT. Establishment of ECBT is the best way that MTE have tired to maintain and conserve elephants and mahouts after implementation of logging ban by earning income from ecotourism, by maintaining the nature with awareness from people and by enhancing the social welfare of mahouts. The interesting and participation of the tourists is the main factor in developing ECBT in nationwide for ecotourism. Thus, promotion to visit ECBT needs different cultures and different attractions in every ECBT even the main is showing elephants and encourages others biodiversity in elephant conservation camps like medical plant garden, and other small wildlife. Therefore, it is necessary to develop ECBT these are, cooperation and collaboration with the International/local NGOs and the other interested parties for the conservation of Elephants in Myanmar, foundation of Elephant Museum \& Elephant Hospital, construction of the required facilities and infrastructure, excursion to the experienced countries as a part of Capacity Building Procedure, foundation of Mahout training center and recruitment of the experts from related fields. The management should take the developing ECBT demand into account by combining with sustainable management of natural forests, conservation of elephants and development of mahouts welfare.

\section{ACKNOWLEDGEMENT}

The authors are grateful to APFNet (Asia Pacific Network for Sustainable Forest Management and Rehabilitation) for granting the scholarship for the first author: ZAR ZAR WIN THEIN to pursue M.Sc degree in forest Economic and Management at Beijing Forestry University. We also thank to staff officers from Head office of Myanma Timber Enterprise (MTE) for the valuable pieces of information. In addition, special thanks goes to the Ministry of Natural Resources and Environmental Conservation (MONREC), and MTE of Myanmar for allowing first author to study abroad.

\section{REFERENCES}

1. (2008) Modeling population viability of captive elephants in Myanmar (Burma)-implications for wild populations. Animal Conservation 11: 198-205

2. Aung, M. (1997). On the distribution, status and conservation of wild elephants in Myanmar. Gajah. 18: 47-55

3. Beaumont, P. (1991). Burma/Myanmar - Illegal trade threat to timber-camp elephants. IUCN/SSC Asian Elephant Specialist Group Newsletter. 6: 21-22

4. Burma Wildlife Protection Act of 1936 (revised 1956)

5. Caughley G (1980) Comments on elephants in Burma. Gajah 14: 1-9.Caughley, G. (1995). Comments on elephants in Burma. Gajah. 14: 1-9 Schmidt, M. J. \& Mar, K. U. (1996). Reproductive performance of captive Asian elephants in Myanmar. Gajah. 2342.docrep/005/ad031e/ad031e0d.htm>

6. Elephant in Myanmar. In: Giants on Our Hands: Proceedings of the International Workshop on the Domesticated Asian Elephant. Baker I \& Kashio M (eds) UN FAO Regional 
Office for Asia and the Pacific, Bangkok. pp 89-102 <www.fao.org/

7. Forest Resource Assessment (FRA) 2015

8. Htun, W. (1996). Status of elephants in the Sathaymyaung Elephant Camp, Myanmar (Burma). Gajah. 16: 69-70

9. Katsuto Shimizu, Oumer S.Ahmed, Raul Ponce-Hernandez, Tetsuji Ota, Zar Chi Win, Nobuya Mizoue and Shigejiro Yoshida (2017), Arrtibution of Disturbance Agents to Forest Change Using a Landsat Time Series in Tropical Seasonal Forests in the Bago Mountains, Myanmar

10. Kyaw Htike powerpoint (2018), Role of Elephant in Myanmar

11. Kyaw Kyaw Lwin powerpoint, Evaluation of Sustainable forest Management and Situation of Forest Resources in Myanmar

12. Lair RC (1997) Myanmar. In: Gone Astray: The Care and Management of the Asian Elephant in Domesticity. UN FAO Regional Office for Asia and the Pacific, Bangkok. pp 99131 www.fao.org/DOCREP/005/AC774E/AC774E00.HTM

13. Leimgruber P \& Wemmer C (2004) National Elephant Symposium and Workshop. Report to the USFWS and the Myanmar Forest Department.

14. Leimgruber P, Senior B, Uga, Myint Aung, Songer MA, Mueller T, Wemmer C \& Ballou J

15. Leimgruber, P., Gagnon, J., Wemmer, C., Kelly, D., Songer, M., \& Selig, E. (2003). Fragmentation of Asia's remaining wildlands: Implications for Asian elephant conservation. Animal Conservation, 6(4), 347-359. doi:10.1017/S1367943003003421.

16. Leimgruber, P., Min-Oo, Z., Aung, M., Kelly, D. S., Wemmer, C., Senior B. \& Songer, M. (2012). Current status of Asian elephants in Myanmar. Gajah. 35: 76-86.

17. Nick Kontogeorgopoulos_(2008) wildlife tourism in semicaptive settings: a case study of elephant camps in northern Thailand

18. Nooteboom, H. P. (1992). A short report on the status of the elephants in Burma (based on a visit to Burma in January 1992). Gajah. 9: 30-31.

19. Olivier RCD (1978) On the Ecology of the Asian Elephant Elephas maximus Linn.: With Particular Reference to Malaya and Sri Lanka. Ph.D. thesis, University of Cambridge, UK.

20. Oo, Z. M. (2010). The training methods used in Myanmar Timber Enterprise. Gajah. 33: 58-61.

21. Oo, Z. M. (2012). Health issues of captive Asian elephants in Myanmar. Gajah. 36: 21-22.

22. Oo, Z. M., Kyaw, W. O. M., Nyunt, T. \& Khaing, A. T. (2009). The occurrence of microfilaria and the response of microfilaria and gut nematodes to ivermectin therapy in Myanmar timber elephants. Gajah. 31: 40-45.

23. Saw John Shwe Ba powerpoint (2017), Role of MTE in Myanmar Timber Industry.

24. The Elephant Preservation Act of 1879.

25. The Protection of Wildlife and Wild Plants and Conservation of Natural Areas Law in (1994).

26. The Protection of Wildlife and Wild Plants and Conservation of Natural Areas Law (1994), in No(16 ) (b) .

27. Toke Gale (1974) Burmese Timber Elephant. Trade Corporation, Rangoon.

28. U khin Zaw (2017), Utilization of Elephants in Timber Harvesting in Myanmar, GAJAH 17:9-22).

29. Vigne, L. \& Martin, E. (2002). Myanmar's ivory trade threatens wild elephants. Gajah. 21: 85-86.

30. Wildlife Protection (Amendment) Act 1956.

31. Williams, A. C. \& Johnsingh, A. J. T (1997). Comment on reproductive performance of timber elephants in Myanmar. Gajah. 18: 61-62.

32. Working People's Settlement Board(1982).

33. Zaw, U. K. (1997). Utilization of elephants in timber harvesting in Myanmar. Gajah. 17: 9-22 